Diabetologia (1993) 36: 1155-1162

\title{
Insulin autoantibodies and high titre islet cell antibodies are preferentially associated with the HLA DQA1*0301-DQB1*0302 haplotype at clinical onset of Type 1 (insulin-dependent) diabetes mellitus before age 10 years, but not at onset between age 10 and 40 years
}

\author{
C. L. Vandewalle ${ }^{1}$,T. Decraene ${ }^{1}$, F.C.Schuit ${ }^{1}$, I. H. De Leeuw ${ }^{2}$, D.G.Pipeleers ${ }^{1}$, F. K. Gorus ${ }^{1}$, \\ the Belgian Diabetes Registry ${ }^{3}$ \\ 'Diabetes Research Centre, Vrije Universiteit Brussel, Brussels, Belgium \\ ${ }^{2}$ Department of Endocrinology, Universitaire Instelling Antwerpen, Antwerp, Belgium \\ ${ }^{3} \mathrm{BDR}$, Brussels, Belgium
}

Summary. Demographic and biological data were collected from all Caucasian Type 1 diabetic patients $(n=279)$ who were recruited at clinical onset by the Belgian Diabetes Registry over 34 months. The male/female ratio was significantly higher for onset between age 20 and 40 years (2.4) than before age 20 years (1.0); no age-or sex-differences were noticed in serum fructosamine concentration. Total and high concentrations of insulin autoantibodies and islet cell antibodies were preferentially associated with the HLA DQA1*0301-DQB1*0302 susceptibility haplotype. The occurrence of both types of antibodies was also correlated, irrespective of haplotype. At onset before age 10 years, the high risk genotype DQA1*0301-DQB1*0302/DQA1*0501 DQB1*0201 was more prevalent than all other DQA1DQB1 genotypes taken together, leading to a higher prevalence of the DQA1*0301-DQB $1 * 0302$ haplotype in this age group ( $75 \%$ ) than in the $10-39$ years age group $(54 \%)$. Under age 10 years, the presence of DQA1*0301DQB $1 * 0302$ was strongly associated with insulin autoantibodies $(90 \%)$ and islet cell autoantibodies $(92 \%$ with $85 \%$ of high titre), whereas patients without this haplotype were less frequently positive for insulin autoantibodies $(31 \%)$ or islet cell autoantibodies ( $38 \%$ high titre). In the group with onset at age 10-39 years, the DQA1*0301-DQB $1 * 0302$ haplotype presented a lower association with insulin autoantibodies ( $40 \%$ ) and islet cell autoantibodies ( 50 to $65 \%$ high titre), prevalences which no longer differed from those in subjects lacking this haplotype. The present data demonstrate that variations in prevalence of insulin autoantibodies and islet cell autoantibodies at onset of Type 1 diabetes can result from differences in age and in the fraction of patients with the HLA DQA1*0301-DQB1*0302 haplotype. The presence of this susceptibility haplotype at onset under age 10 years identifies a sub-group of patients with more than $90 \%$ positivity for insulin autoantibodies and more than $90 \%$ positivity for islet cell autoantibodies. It is conceivable that this sub-group can be recognized in the pre-diabetic phase through screening for immunological and genetic markers.

Key words: Diabetes mellitus, insulin autoantibodies, islet cell antibodies, HLA DQ genotyping, diabetes registries.
Despite the emergence of new promising immune markers for Type 1 (insulin-dependent) diabetes mellitus [1-3], autoantibodies directed against as yet undefined islet cell cytoplasmic antigens (islet cell cytoplasmic antibodies; ICA) and against insulin (insulin autoantibodies; IAA) are presently the only available antibody tests that are applicable to population screening for individuals at risk [4-10]. Genetic risk for Type 1 diabetes has been associated with the presence or absence of HLA DQA1DQB1 susceptibility haplotypes such as DQA1*0301$\mathrm{DQB} 1 * 0302$ or $\mathrm{DQA} 1 * 0501-\mathrm{DQB} 1 * 0201$ and, even more so, with the specific genotypic combination of maternally and paternally inherited DQA1-DQB1 haplotypes [11-16]. Recent studies have suggested that immunological and genetic risk markers for Type 1 diabetes can be preferentially associated $[17-20]$ creating the per- spective that joint determination of markers might increase the success at which the disease can be predicted. Long-term prospective studies are needed to assess this possibility. It is, in this context, important to know whether and how these immunological and genetic markers are associated at the end-point of the preclinical phase of the disease, i.e. the time of clinical onset [21]. In the present study we assess the association of ICA and IAA with the presence of specific HLA DQA1-DQB1 susceptibility haplotypes and genotypes in 279 Caucasian Type 1 diabetic patients under age 40 years, sampled at clinical onset. 


\section{Subjects and methods}

\section{Subjects}

Between June 1989 and March 1992, 540 Caucasians with recentonset Type 1 diabetes were consecutively recruited by the Belgian Diabetes Registry, a national data and sample bank for newly diagnosed Type 1 diabetic patients and their first degree relatives under age 40 years [22]. The registry collects data on approximately $40 \%$ of all new cases of Type 1 diabetes in Belgium. In 279 patients, blood could be sampled before start of insulin therapy or, at the latest, within 7 days of initial treatment for determination of IAA, ICA, fructosamine and HLA DQ genotyping; only these samples were used for further analysis. The age- and sex-distribution of the 279 studied patients did not differ significantly from the values observed in all registered patients, which also included patients not sampled at onset. In this larger group $(n=540), 49 \%$ of the subjects developed the disease before age 20 years and $58 \%$ were males; the male/female ratio was 1.0 for onset before age 20 years and 1.8 for onset between age 20 and 40 years $(n=540)$. The diagnosis of Type 1 diabetes was assessed according to the criteria of the National Diabetes Data Group [23]. The group with patients sampled at onset comprised 170 males and 109 females (Table 1). Irrespective of age and ICA-positivity at onset, the presence of ketonuria was reported in over $85 \%$ of the patients. C-peptide values (determined locally) were only available in a minority of cases, rendering comparisons difficult. Healthy Caucasian control subjects $(n=362)$ were randomly recruited in the provinces of Antwerp and Brabant for HLA DQ genotyping and comprised 203 males (56\%) and 159 females ( $44 \%$ ) with a mean age of 16 years (range $0-39$ years).

\section{HLA-DQ genotyping}

DNA was extracted from EDTA-blood and stored at $-20^{\circ} \mathrm{C}$. Part of the second exon of the DQA1 and DQB1 genes was amplified in vitro by polymerase chain reaction (PCR) using Taq DNA-polymerase [16]. Amplified DNA was dot-blotted on a nylon membrane and hybridized to a panel of 15 different ${ }^{32} \mathrm{P} 5^{\prime}$ end-labelled allele-specific oligonucleotide probes (see [16] for sequences of primers and probes). The latest nomenclature of the World Health Organization committee for factors of the HLA system was used [24].

\section{IAA testing}

IAA were measured by radiobinding assay, according to a modification [25] of the original Palmer-protocol [26,27] and validated in successive Immunology of Diabetes Workshops for IAA-standardization [25]. Sera with IAA-concentrations greater than or equal to $0.7 \%$ (mean $+3 \mathrm{SD}$ of 196 healthy control subjects with a mean age of 20 years; range 1-40 years) were scored positive and results greater than or equal to $1.5 \%$ (mean $+10 \mathrm{SD}$ of healthy control subjects) were considered to be high concentrations.

\section{ICA testing}

ICA were measured by an immunohistochemical assay using cryosections of fresh-frozen human pancreas (blood group $O$ ) as substrate. A modification of the method of Bottazzo et al. [28] was used. Briefly, $6 \mu \mathrm{m}$ cryosections of unfixed human blood group $\mathrm{O}$ pancreas were air-dried on glass slides. Serum samples were diluted ten-fold in phosphate buffered saline (PBS: $7.52 \mathrm{~g} \mathrm{~K}_{2} \mathrm{HPO}_{4} \cdot 3 \mathrm{H}_{2} \mathrm{O}$, $1.32 \mathrm{~g} \mathrm{NaH}_{2} \mathrm{PO}_{4} \cdot 2 \mathrm{H}_{2} \mathrm{O}, 7.2 \mathrm{~g} \mathrm{NaCl}$ per litre, $\mathrm{pH} 7.3$ ) containing $15 \mathrm{~g}$ bovine serum albumin (BSA, fraction V, RIA-grade; Sigma Chemical Corp, St. Louis, Mo. USA) and $20 \mathrm{mmol}$ benzamidine (AldrichEurope, Beersel, Belgium) per litre. Diluted serum $(100 \mu 1)$ was layered on the section and incubated overnight at $4^{\circ} \mathrm{C}$. The slides were washed with PBS and again incubated for $30 \mathrm{~min}$ at room tem- perature with FITC (fluorescein isothiocyanate)-labelled rabbit anti-human $\mathrm{IgG} F$ c fragment antiserum (Dakopatts, Glostrup, Denmark) diluted 1/40 in PBS. The slides were washed again and evaluated under a fluorescence microscope (Carl Zeiss, Oberkochen, Germany) by two independent observers. When positive at the initial dilution, further serial two-fold dilution steps were evaluated to determine the end-point titre (highest positive dilution). Positive and negative control sera were included in each assay for internal quality control. The end-point titres were converted to Juvenile Diabetes Foundation units (JDFU) through a standard curve obtained by plotting the end-point titres for different dilutions of a JDF standard serum against their assigned values in JDFU. Sera from 196 healthy control subjects (mean age of 20 years; range $1-40$ years) were all ICA-negative, except two samples which contained 6 JDFU. Therefore a titre of at least 12 JDFU was considered to be increased and results greater than or equal to 50 JDFU were considered to represent high titres. The test was clinically validated through repeated participation in external quality control programmes (IDW-workshops) [25].

\section{Fructosamine testing}

Serum fructosamine was measured with a commercial kit [29] (TestCombination Fructosamine, kit N 1-298-194; Boehringer Mannheim, Mannheim, Germany) adapted to a Cobas-Bio centrifugal analyser (Hoffman-LaRoche, Basel, Switzerland) [30]. Age-adjusted reference values were determined by analysing sera from 195 healthy control subjects (aged 0-39 years) comprising children and adolescents attending the paediatric department $(n=136)$, blood donors and laboratory workers $(n=59)$. The 1 st and 99 th percentiles were taken as the lower, respectively upper limit of the reference interval for each age category (reference range for 0-2 years: 148 $281 \mu \mathrm{mol} / \mathrm{l}$; 3-5 years: $204-276 \mu \mathrm{mol} / \mathrm{l} ; 6-8$ years: $211-284 \mu \mathrm{mol} / \mathrm{l}$; 9-11 years: 201-282 $\mu \mathrm{mol} / \mathrm{l}: \quad 12-14$ years: $225-280 \mu \mathrm{mol} / \mathrm{l} ; \quad 15-$ 17 years: $213-290 \mu \mathrm{mol} / \mathrm{l}: 18-39$ years: $229-306 \mu \mathrm{mol} / \mathrm{l}$ ).

\section{Statistical analysis}

A chi-squared test was used to estimate overall statistical differences in prevalence between multiple groups. In the particular case of two groups, a chi-squared test with Yates' correction or Fisher's exact test

Table 1. Demographic and metabolic characteristics of patients with recent-onset Type 1 diabetes

\begin{tabular}{llll}
\hline Characteristics & \multicolumn{3}{l}{ Type 1 diabetic patients } \\
\cline { 2 - 4 } & Total & $0-19$ years & $20-39$ years \\
\hline$n$ & 279 & $126(45)$ & $153(55)$ \\
Sex & & & \\
$\quad$ male $(\mathrm{M})$ & 170 & $62(36)$ & $108(64)$ \\
$\quad$ female $(\mathrm{F})$ & 109 & $64(59)$ & $45(41)$ \\
$\quad$ M/F ratio & 1.6 & $1.0^{\mathrm{b}}$ & 2.4 \\
Age (years) & & & \\
$\quad$ mean \pm SD & $21 \pm 11$ & $11 \pm 5$ & $29 \pm 5$ \\
$\quad$ median & 21 & 11 & 30 \\
$\quad$ range & $0-39$ & $0-19$ & $20-39$ \\
Fructosamine $(\mu \mathrm{mol} / 1)$ & & & \\
$\quad$ mean \pm SD & $615 \pm 151$ & $622 \pm 161$ & $609 \pm 142$ \\
$\quad$ median & 609 & 617 & 595 \\
$\quad$ range & $223-1105$ & $223-1038$ & $284-1105$ \\
$\quad$ positivity & & & \\
$\quad>99^{\text {th }}$ percentile & $268 / 271$ & $120 / 121(99)$ & $148 / 150(99)$ \\
\hline
\end{tabular}

Values in parentheses are percentages.

${ }^{\mathrm{a}}$ Male/female ratio; ${ }^{\mathrm{b}} p<0.001$ vs $20-39$ years 
Table 2. Association between HLA DQA1-DQB1 haplotypes and autoantibodies (IAA, insulin autoantibodies; ICA, islet cell autoantibodies) in patients with recent-onset Type 1 diabetes

\begin{tabular}{|c|c|c|c|c|c|}
\hline \multicolumn{2}{|c|}{ DQA1*-DQB1*haplotypes } & \multicolumn{4}{|c|}{ Prevalence of autoantibodies } \\
\hline \multirow[t]{2}{*}{ Type } & \multirow[t]{2}{*}{ Prevalence } & \multicolumn{2}{|c|}{$\mathrm{IAA}$} & \multicolumn{2}{|l|}{ ICA } \\
\hline & & $\geq 0.7 \%$ & $\geq 1.5 \%$ & $\geq 12 \mathrm{JDFU}^{\mathrm{a}}$ & $\geq 50 \mathrm{JDFU}$ \\
\hline Non-(0301-0302) & $118 / 279(42)$ & $34 / 118(29)$ & $15 / 118(13)$ & $72 / 118(61)$ & $52 / 118(44)$ \\
\hline$p$ & & $<0.001$ & $<0.005$ & $<0.005$ & $<0.005$ \\
\hline $0501-0201$ & $157 / 279(56)$ & $68 / 157(43)$ & $33 / 157(21)$ & $109 / 157(69)$ & $84 / 157(54)$ \\
\hline
\end{tabular}

Values in parentheses are percentages.

a JDFU, Juvenile Diabetes Foundation units

were used whenever appropriate. The results of tests yielding a $p$ value exceeding 0.05 were denoted as NS (not significant). In case of multiple comparisons, $p$ values had to be smaller than a level of significance defined as 0.05 divided by the number of comparisons (Bonferroni). The Mann-Whitney U test was used to compare median values from two independent groups. All statistical tests were performed two-tailed. Relative risk (RR) was calculated from the formula $R R=\left(a^{*} d\right) /\left(b^{*} c\right)$ in which a and $c$ are the numbers of patients and control subjects presenting a given marker (HLA haplotype or-genotype) and $b$ and $d$ are the numbers of marker-negative patients and control subjects [31]. When an element of this equation was zero, $\mathrm{RR}$ was calculated with the Haldane formula [16]: $\mathrm{RR}=$ $(2 \mathrm{a}+1) *(2 \mathrm{~d}+1) /(2 \mathrm{~b}+1) *(2 \mathrm{c}+1)$.

\section{Results}

\section{Demographic and metabolic data}

The studied Type 1 diabetic patients were equally distributed among the age groups $0-19$ years and $20-39$ years (Table 1 ). Below age 20 , the male/female ratio (M/F) approximated 1 , but in the older age group, there was a significant excess of male patients $(\mathrm{M} / \mathrm{F}=2.4)$. Fructosamine concentrations were not significantly different between both age groups and exceeded the 99th percentile of ageadjusted reference ranges in $99 \%$ of the patients for whom sufficient serum was available for fructosamine testing (268 of 271). Fructosamine concentrations did not differ significantly between males and females and were not correlated with age at onset or with IAA or ICA concentrations (results not shown).

\section{Association between HLA DQ haplotypes and autoantibodies}

The prevalence of both IAA ( $\geq 0.7 \%)$ and ICA $(\geq 12$ JDFU) was significantly higher in Type 1 diabetic patients carrying at least one copy of the IILA DQA $1 * 0301$ DQB $1 * 0302$ diabetes susceptibility haplotype, but did not differ according to the presence or absence of the HLA DQA1*0501-DQB1*0201 susceptibility haplotype (Table 2). Patients carrying at least one copy of DQA1*0301-DQB $1 * 0302$ also more frequently presented high concentrations of IAA ( $\geq 1.5 \%$; corresponding to the mean of control subjects $+10 \mathrm{SD})$, and high titre ICA
Table 3. Association between HLA DQA1-DQB1 genotypes and autoantibodies (IAA, insulin autoantibodies; ICA, islet cell autoantibodies) in patients with recent-onset Type 1 diabetes

\begin{tabular}{lllll}
\hline DQA1*-DQB1* genotypes & & \multicolumn{2}{l}{ Prevalence of autoantibodies } \\
\cline { 1 - 2 } \cline { 5 - 6 } Type & Prevalence & & $\begin{array}{l}\text { IAA } \\
(\geq 0.7 \%)\end{array}$ & \multicolumn{1}{l}{$\begin{array}{l}\text { ICA } \\
\left(\geq 12 \text { JDFU }^{\mathrm{a}}\right)\end{array}$} \\
\hline $0301-0302 / 0501-0201$ & $82 / 279(29)$ & $45 / 82(55)^{\mathrm{b}}$ & $62 / 82(76)$ \\
$0301-0302 / 0301-0302$ & $17 / 279(6)$ & $7 / 17(41)$ & $16 / 17(94)^{\mathrm{c}}$ \\
$0501-0201 / 0501-0201$ & $25 / 279(9)$ & $7 / 25(28)$ & $15 / 25(60)$ \\
$0301-0302 / \mathrm{X}^{\mathrm{d}}$ & $62 / 279(22)$ & & $31 / 62(50)^{\mathrm{c}}$ & $46 / 62(74)$ \\
$0501-0201 / \mathrm{X}$ & $50 / 279(18)$ & & $16 / 50(32)$ & $32 / 50(64)$ \\
$\mathrm{X} / \mathrm{X}$ & $43 / 279(15)$ & $11 / 43(26)$ & $25 / 43(58)$ \\
$p^{\mathrm{a}}$ & & $<0.01$ & $<0.05$ \\
\hline
\end{tabular}

Values in parentheses are percentages.

a JDFU, Juvenile Diabetes Foundation units; ${ }^{b} p<0.005,{ }^{\circ} p<0.02$ vs prevalence in patients with $\mathrm{X} / \mathrm{X}$ genotype (uncorrected); ${ }^{\mathrm{d}} \mathrm{X}$, other haplotype than DQA1*0301-DQB1*0302 or DQA1*0501DQB1*0201; " Overall statistical significance of differences in prevalence between six genotype groups

( $\geq 50 \mathrm{JDFU}$ ) as compared to patients lacking this haplotype. Again, no such differences in antibody prevalence existed in patients with or without DQA1*0501-DQB1*0201 (Table 2).

\section{Association between HLA DQ genotypes and autoantibodies}

To assess any associations of autoantibody prevalence with specific DQA1-DQB1 genotypes, we divided subjects into the following six groups on the basis of the possible combinations of DQA1-DQB1 susceptibility haplotypes into genotypes: 0301-0302/0501-0201, 03010302/0301-0302,0501-0201/0501-0201,0301-0302/X, 05010201/X and $\mathrm{X} / \mathrm{X}$ where $\mathrm{X}$ represents any haplotype other than 0301-0302 or 0501-0201. According to the frequency of these genotypes in the presently studied patients at onset and in a large cohort of non-diabetic control individuals [16], the RR for Type 1 diabetes conferred by these various genotypes amounted respectively to 31.5, 9.9, 2.6, $1.9,1.0$ and 0.2 .

The prevalences of IAA $(\geq 0.7 \%)$ and ICA $(\geq 12$ JDFU) were overall significantly different between the various genotypes (Table 3 ). Higher values for IAA-prevalence $(\geq 40 \%)$ and ICA-prevalence $(\geq 70 \%)$ were 
Table 4. Prevalence of insulin autoantibodies (IAA), islet cell autoantibodies (ICA) and HLA DQA1*0301-DQB1*0302 containing genotypes in recent-onset Type 1 diabetic patients subdivided according to age

\begin{tabular}{|c|c|c|c|c|c|c|}
\hline $\begin{array}{l}\text { Age groups } \\
\text { (years) }\end{array}$ & $n$ & $\begin{array}{l}\text { IAA } \\
\geq 0.7 \%\end{array}$ & $\begin{array}{l}\text { ICA } \\
\geq 12 \mathrm{JDFU}^{\mathrm{a}}\end{array}$ & $\begin{array}{l}0301-0302 \\
\text { haplotype }\end{array}$ & $\begin{array}{l}0301-0302 / \\
0501-0201\end{array}$ & $\begin{array}{l}0301-0302 \\
0301-0302\end{array}$ \\
\hline $0-9$ & 52 & $39(75)$ & $44(85)$ & $39(75)$ & $28(54)$ & $1(2)$ \\
\hline $10-19$ & 74 & $33(45)$ & $62(84)$ & $43(58)$ & $22(30)$ & $6(8)$ \\
\hline $30-39$ & 81 & $20(25)$ & $41(51)$ & $43(53)$ & $16(20)$ & $6(7)$ \\
\hline$p^{\mathrm{b}}$ & & $<0.001$ & $<0.001$ & $<0.05$ & $<0.001$ & NS \\
\hline
\end{tabular}

Values in parentheses are percentages.

${ }^{\mathrm{a}}$ JDFU, Juvenile Diabetes Foundation units; ${ }^{b}$ Overall statistical significance of differences in prevalence between the four age groups

Table 5. Prevalence of insulin autoantibodies (IAA) and islet cell autoantibodies (ICA) in Type 1 diabetic patients subdivided according to age and sex

\begin{tabular}{|c|c|c|c|c|c|c|}
\hline \multirow{2}{*}{$\begin{array}{l}\text { Age } \\
\text { (years) }\end{array}$} & \multicolumn{3}{|c|}{ Males } & \multicolumn{3}{|c|}{ Females } \\
\hline & $n$ & IAA $(\geq 0.7 \%)$ & $\operatorname{ICA}\left(\geq 12 \mathrm{JDFU}^{\mathrm{a}}\right)$ & $n$ & IAA $(\geq 0.7 \%)$ & ICA ( $\geq 12$ JDFU $)$ \\
\hline $0-9$ & 22 & $15(68)$ & $18(82)$ & 30 & $24(80)$ & $26(87)$ \\
\hline $10-19$ & 40 & $18(45)$ & $33(82)$ & 34 & $15(44)$ & $29(85)$ \\
\hline $30-39$ & 58 & $13(22)$ & $28(48)$ & 23 & $7(30)$ & $13(56)$ \\
\hline$p^{\text {b }}$ & & $<0.001$ & $<0.002$ & & $<0.002$ & $<0.05$ \\
\hline
\end{tabular}

Values in parentheses are percentages.

${ }^{\mathrm{a}}$ JDFU, Juvenile Diabetes Foundation units; ${ }^{\mathrm{b}}$ Overall statistical significance of differences in prevalence between the four age groups

found in genotypes with a least one DQA1*0301DQB $1 * 0302$ haplotype. Compared to patients without risk haplotypes $(\mathrm{X} / \mathrm{X})$, patients with the high risk heterozygous genotype DQA $1 * 0301-\mathrm{DQB} 1 * 0302 / \mathrm{DQA} 1-$ *0501-DQB1*0201 or with the DQA1*0301-DQB1*0302/X genotype had an increased prevalence of IAA, and homozygotes for DQA $1 * 0301-\mathrm{DQB} 1 * 0302$ displayed an increased prevalence of ICA (Table 3 ). It is noteworthy that in the latter group all but one of the subjects were ICA-positive. After correcting for the number of comparisons (Bonferroni) only the association between the high risk heterozygous genotype and IAA remained significantly different. Prevalence of IAA or ICA did not differ significantly among the various DQA1 *0301-DQB1*0302 containing genotypes (Table 3).

\section{Association between IAA and ICA}

Without considering presence or absence of HLA DQ susceptibility haplotypes, IAA were more frequently present in ICA-positive ( $\geq 12$ JDFU) patients (98 of 196) than in ICA-negative ones (19 of $83 ; p<0.001)$. This association between IAA and ICA was also demonstrable in subjects carrying at least one copy of the DQA1*0301-DQB1*0302 haplotype (71 of 124 vs 12 of $37 ; p<0.01)$ as well as in subjects without this haplotype ( 27 of 72 vs 7 of $46 ; p<0.01$ ). Conversely, ICA-positivity occurred more frequently in IAA-positive patients (98 of 117) than in IAA-negative subjects (98 of 162), without considering differences in HLA DQ haplotypes $(p<0.001)$. This association remained demonstrable in the presence ( 71 of 83 vs 53 of $78 ; p<0.01$ ) or absence (27 of 34 vs 45 of $84 ; p<0.01$ ) of DQA1*0301DQB $1 * 0302$.

\section{Association of biological markers with age and sex}

The occurrence of IAA, ICA and diabetes susceptibility haplotypes and genotypes was further investigated as a function of age at onset and sex (Table 4). With the exception of homozygosity for DQA $1 * 0301-\mathrm{DQB} 1 * 0302$, the tested immune and genetic markers were more prevalent in patients with younger age at clinical onset. The IAA-positive subjects were significantly younger than the IAA-negative ones (median age: 15 years and 26 years, respectively; $p<0.001$ ), the ICA-positive subjects were younger than the ICA-negative ones (median age: 18 years and 30 years, respectively: $p<0.001$ ), and the subjects with the high risk heterozygous genotype DQA1*0301-DQB1*0302/DQA1*0501-DQB1$* 0201$ were younger than the others (median age: 16 years and 23 years, respectively; $p<0.001$ ). Nevertheless, $92 \%$ of patients with onset after age 20 years were positive for at least one type of autoantibody or carried at least one HLA-DQ susceptibility haplotype. Overall, autoantibodies were more prevalent in females than in males (for IAA: $51 \%$ vs $36 \%, p<0.02$; for ICA: $77 \%$ vs $66 \%, p<0.05)$.

In view of the increase in male/female ratio in patients with onset after age 20 years and of the age- and sex-dependent occurrence of IAA and ICA at clinical manifestation, we compared the prevalence of both immune markers in patients grouped according to age at onset and sex. IAA-prevalence decreased significantly with age at onset in both sexes (Table 5), especially from age 10 years and older. For ICA, a significant decline of prevalence with age was also observed in both sexes, especially from age 20 years and older (Table 5). When considering the 10 - or 20-year age groups, males and females did not differ significantly in prevalence of IAA, ICA, the DQA1*0301- 
Table 6. Prevalence of insulin autoantibodies (IAA) and islet cell autoantibodies (ICA) in Type 1 diabetic patients of different age groups $(0-9$ years, $n=52 ; 10-19$ years, $n=74 ; 20-39$ years, $n=153)$ after classification according to HLA DQA $1 *$-DQB $1 *$ genotype

\begin{tabular}{|c|c|c|c|c|c|c|c|c|}
\hline \multirow{3}{*}{$\begin{array}{l}\text { DQA } 1 * \text {-DQB1* } \\
\text { genotype }\end{array}$} & \multirow{3}{*}{$\begin{array}{l}\text { Age } \\
\text { (years) }\end{array}$} & \multirow[b]{3}{*}{$n(\%)$} & \multirow[b]{3}{*}{$\mathrm{RR}^{\mathrm{a}}$} & \multirow{3}{*}{$\begin{array}{l}\text { Sex } \\
\text { ratio }^{b}\end{array}$} & \multicolumn{4}{|c|}{ Prevalence of autoantibodies } \\
\hline & & & & & \multicolumn{2}{|c|}{ IAA } & \multicolumn{2}{|l|}{ ICA } \\
\hline & & & & & $\geq 0.7 \%$ & $\geq 1.5 \%$ & $\geq 12 \mathrm{JDFU}^{\circ}$ & $\geq 50 \mathrm{JDFU}$ \\
\hline \multirow[t]{2}{*}{ Any haplotype } & $10-19$ & $43(58)$ & 5.0 & $1.1^{\mathrm{d}}$ & $19(44)$ & $12(28)$ & $37(86)$ & $28(65)$ \\
\hline & $20-39$ & $79(52)$ & 5.6 & $1.9^{\mathrm{d}}$ & $29(37)$ & $11(14)$ & $51(65)$ & $39(49)$ \\
\hline$p$ & & $<0.02$ & & $<0.05$ & $<0.001$ & $<0.001$ & $<0.001$ & $<0.001$ \\
\hline 0501-0201 & $20-39$ & $32(21)$ & 19.4 & 1.9 & $10(31)$ & $4(12)$ & $20(62)$ & $15(47)$ \\
\hline$p$ & & $<0.001$ & & NS & $<0.001$ & $<0.005$ & NS & $<0.05$ \\
\hline $0301-0302 i$ & $0-9$ & $11(21)$ & 3.0 & 0.8 & $11(100)^{g}$ & $8(73)^{\mathrm{k}}$ & $11(100)^{\mathrm{k}}$ & $11(100)^{\mathrm{h}}$ \\
\hline \multirow{2}{*}{ Non(0501-0201) } & $10-19$ & $21(28)$ & 1.7 & 0.8 & $8(38)$ & $6(29)$ & $20(95)$ & $14(67)$ \\
\hline & $20-39$ & 47 (31) & 2.6 & 1.9 & $19(40)$ & $7(15)$ & $31(66)$ & $24(51)$ \\
\hline$p$ & & NS & & NS & $<0.002$ & $<0.001$ & $<0.005$ & $<0.01$ \\
\hline & & $<0.02$ & & $<0.05$ & NS & NS & $<0.05$ & $<0.05$ \\
\hline
\end{tabular}

Values in parentheses are percentages.

${ }^{a}$ RR, Relative risk; ${ }^{\mathrm{b}}$ Male/female ratio; ${ }^{\mathrm{c}}$ JDFU, Juvenile Diabetes Foundation units; ${ }^{d}$ NS vs sex ratio in corresponding age groups with other genotype; ${ }^{\mathrm{e}} p<0.02$ and ${ }^{\mathrm{f}} p<0.05$ vs sex ratio in patients, ages

DQB $1 * 0302$ haplotype or the high risk heterozygous genotype (data not shown).

Genotypes comprising at least one copy of DQA $1 * 0301-\mathrm{DQB} 1 * 0302$ occurred more frequently in younger (0-9 years) than in older (10-39 years) patients (Table 6). This association was exclusively attributed to the higher prevalence of the high risk heterozygous genotype DQA1*0301-DQB1*0302/DQA1*0501-DQB1$* 0201$ in patients under age 10 years. The prevalence of the other DQA $1 * 0301-\mathrm{DQB} 1 * 0302$ containing genotypes did not differ significantly among age groups (Table 6). Conversely, genotypes lacking DQA $1 * 0301-\mathrm{DQB} 1 * 0302$ occurred relatively more frequently at later age of onset (Table 6). Comparison of the relative abundance of a given genotype in patients aged 0-9 years, $10-19$ years or 20-39 years and in age-matched control subjects, allowed estimation of the RR conferred by this genotype in a particular age group. The high risk heterozygous genotype exhibited - as expected - the highest RR for Type 1 diabetes, being more than two-fold higher under age 10 years (RR 51) than in the 10-39 years age group (RR 13 to 19). The other genotypes carrying a DQA1*0301-DQB1*0302 haplotype exhibited only a slightly increased risk (RR 1.5 to 3) without age-dependency. Within these various genetically defined groups, the male/female ratio changed with age at onset, being invariably below 1 in patients under age 10 years (range $0.7-0.9$ ) and above 1.9 in onset at age 20-39 years (range 1.9-3.1). The highest value (3.1) was observed in subjects, ages 20-39 years, who lacked the DQA $1 * 0301-D Q B 1 * 0302$ haplotype. Sex ratios did not vary significantly with the genotype within each age group (Table 6).

In patients under age 10 , the presence of the DQA1*0301-DQB1*0302 haplotype was associated with
$20-39$ years, with the same genotype; ${ }^{g} p<0.001,{ }^{b} p<0.002$, ${ }^{\mathrm{i}} p<0.005, \mathrm{j} p<0.02$ and $^{\mathrm{k}} p<0.05$ vs prevalence in corresponding age group with non(0301-0302)/non(0301-0302) genotype; ${ }^{1} p<0.01$ vs prevalence in patients, ages $20-39$ years, with the same genotype

$90 \%$ positivity for IAA and $92 \%$ positivity for ICA, $85 \%$ displaying high titre ICA (Table 6). Within this age group, patients carrying the susceptibility haplotype in combination with any other haplotype except DQA1*0501DQB $1 * 0201$, were all positive for IAA and high titre ICA. In the absence of the DQA $1 * 0301-D Q B 1 * 0302$ haplotype, a much lower prevalence of IAA (31\%) and high titre ICA $(38 \%)$ was noted. In patients with onset between age 10 and 40 years, the diabetes susceptibility haplotype DQA1*0301-DQB1*0302 occurred less frequently than in the group under age 10 years and was no longer preferentially associated with IAA and high titre ICA. In the older age categories, the prevalence of these antibodies was not significantly different for patients with or without the DQA1*0301-DQB1*0302 haplotype (Table 6). Overall, the prevalence of (high concentrations of) IAA and ICA decreased significantly with age in the presence of DQA $1 * 0301-D Q B 1 * 0302$, but not or only borderline in its absence (Table 6). For onset under age 10 years, antibody prevalence was significantly higher in presence of DQA $1 * 0301-D Q B 1 * 0302$ than in its absence. In older age groups, this difference was not significant, even without considering corrections for multiple comparisons (Bonferroni).

\section{Discussion}

Systematic collection of data from a large number of Type 1 diabetic patients, with age of onset up to 40 years allows a comparison of biological markers in different age categories $[32,33]$. Our patient group comprised an equal number of males and females under age 20 years. Similar to Sweden [33], a male predominance was seen for clinical 
onset after age 20 years. It is so far unknown whether susceptibility to Type 1 diabetes is increased in males or resistance to the disease is greater in females, nor whether the observed difference is caused by sex-linked differences in life style, by genetic (X- or Y-chromosome-linked) susceptibility factors, or by the hormonal status. In the present study, the excess of male patients with onset after age 20 years appeared independent of the genetic risk conferred by various HLA DQA1-DQB1 genotypes. Nevertheless, it should be noted that the male predominance was most pronounced in 20- to 39-year-old patients lacking the DQA $1 * 0301-D Q B 1 * 0302$ haplotype. A larger study group is required to further investigate this issue. As judged by fructosamine concentrations, the degree of metabolic dysregulation at onset was similar in the age groups $0-19$ years and $20-39$ years and did not differ between males and females.

A high prevalence of IAA- and of ICA-positivity was noted at onset of Type 1 diabetes, which is in agreement with previous work $[10,17,21,26,32-35]$. In contrast to previous studies [32,36-38], the prevalence of IAA and ICA varied according to the HLA DQ haplotype. The presence of IAA was associated with the DQA $1 * 0301-\mathrm{DQB} 1 * 0302$ haplotype, confirming and extending the observation of a preferential occurrence of IAA in DR4-positive Type 1 diabetic patients $[17,39,40]$. Among the various DQA $1 * 0301-\mathrm{DQB} 1 * 0302$ containing genotypes, no significant difference in IAA-prevalence could be demonstrated. A significant association was also observed between (high titre) ICA and the presence of the DQA $1 * 0301-$ DQB $1 * 0302$ haplotype, which contradicts reports describing no relationship between ICAprevalence and HLA DR4 in Type 1 diabetic patients [17, $32,36,40]$, but corroborates other studies describing an association between ICA and HLA DR3 and/or DR4 [41, 42]. In the present series, no significant difference in ICAprevalence was found between various DQA1*0301DQB1*0302-containing genotypes. Irrespective of the presence of the DQA $1 * 0301-D Q B 1 * 0302$ haplotype, ICA and IAA were significantly associated at onset of Type 1 diabetes confirming previous observations $[20,27,39,43]$ and contradicting others $[37,38]$. The discrepancy between various publications investigating possible associations among genetic and immunological markers in Type 1 diabetes might be due to differences in specificity of the tested markers as well as to differences in sensitivity of the assays. In the present study, clear associations between genetic and immunological markers were demonstrated by using antibody assays which have been validated in consecutive IDW-programmes [25] and by genetic analysis of the HLA DQ locus, which is known to be more closely linked to diabetes-susceptibility than HLA DR [11-16].

The frequency of immunological and genetic markers varied significantly with age at onset and sex. In all age groups, antibodies were, in general, more prevalent in females than in males. In agreement with previous reports $[16,25,33,41,44,45]$, but unlike others [17, 32], IAA, ICA (both total and high concentration), the high risk heterozygous genotype and hence the DQA $1 * 0301$ DQB $1 * 0302$ haplotype occurred more frequently at younger age of onset. Only in patients below age 10 years were IAA and ICA preferentially associated with the DQA1*0301-DQB1*0302 haplotype. The higher prevalence of IAA and ICA at younger age of onset may be explained by the combination of this preferential association and the higher prevalence of the DQA1*0301DQB $1 * 0302$ haplotype at onset below age 10 years, which in turn is solely determined by the higher prevalence of the high risk heterozygous genotype in this age group. $\mathrm{Pa}$ tients with onset under age 10 years without the diabetes susceptibility haplotype presented a lower prevalence of autoantibodies, as in all patients with onset at age 10-39. In the latter group, this susceptibility haplotype occurred less frequently because of the lower prevalence of the high risk heterozygous genotype and was no longer preferentially associated with IAA or ICA; autoantibody prevalence was lower and largely independent of the susceptibility haplotype. Reported variations in prevalence and age-dependence of the autoantibody response at onset $[17,32-35,44]$ thus might partly result from betweenstudy differences in the patients' age at onset and in haplotype distribution among subjects. Preferential association of IAA, ICA and susceptibility haplotypes at clinical onset of Type 1 diabetes under age 10 years identifies a sub-group of individuals with more than $90 \%$ positivity for IAA and more than $90 \%$ positivity for ICA. This subgroup may be recognized preclinically through a combination of immunological and genetic markers. It therefore seems interesting to assess associations between genetic and immunological markers in groups of subjects at risk for Type 1 diabetes, e.g. first degree relatives of Type 1 diabetic patients or ICA-positive schoolchildren, and to monitor these markers until the diabetic end-point.

The decreasing frequency of IAA, ICA and high risk heterozygous genotype with age at onset of Type 1 diabetes, also stresses the need to exclude an increasing admixture of Type 2 (non-insulin-dependent) diabetic cases, mistakenly classified as having Type 1 diabetes, in the older age groups [46]. The present study can do this using the following arguments. First, all patients were recruited according to the same clinical criteria [23]. Almost all subjects with onset after age 20 were positive for at least one type of autoantibody or one susceptibility haplotype associated with Type 1 diabetes. Ketonuria was noted at onset in the vast majority of patients, also in the ICA-negative subjects. Secondly, the relative abundance of various HLA DQA1-DQB1 genotypes at different ages of onset was similar to that noted in a previous study in patients with long-term Type 1 diabetes recruited outside the Belgian Diabetes Registry [16]. Furthermore, the decrease in autoantibody prevalence with advancing age at onset was also present in the patients carrying the heterozygous high risk genotype, which is specifically associated with Type 1 diabetes but is very rare in control subjects or patients with Type 2 diabetes [16]. By contrast, the prevalence of (high concentrations of) IAA or ICA was not markedly decreased at later age of onset in the patients without the DQA1*0301-DQB1*0302 susceptibility haplotype. Finally, in the case of IAA and the high risk heterozygous genotype, the frequency of marker positivity started to decline well before age 20 years where significant admixture of Type 2 cases is highly unlikely. 
In conclusion, the present study has confirmed heterogeneity among Type 1 diabetic patients. The disease seems to affect significantly more males than females, for those with onset after age 20 years. In subjects with the high risk heterozygous genotype, the clinical disease appears more frequently before age 10 years and is then more often associated with the presence of (high concentrations of) IAA and ICA. This age-dependent association with autoantibodies also exists in patients with other DQA1*0301DQB $1 * 0302$ containing genotypes, which, however, confer only a moderate and age-independent RR for Type 1 diabetes. Finally, genotypes without DQA1*0301DQB ${ }^{*} 0302$ occur more frequently at later age of onset, confer a low RR for Type 1 diabetes, and are associated with a low, less age-dependent, prevalence of autoantibodies. The presence of DQA1*0301-DQB1*0302 in patients with onset before age 10 years defines a sub-group with more than $90 \%$ positivity for IAA and more than $90 \%$ positivity for ICA raising the question whether this haplotype is also associated with more autoantibody positivity in normal control subjects and first degree relatives under age 10 years.

Acknowledgements. We would like to acknowledge the following members of the Belgian Diabetes Registry who have contributed to the recruitment of patients and control cases or to the handling of samples for the present study: E. Balasse (Brussels), H. Becq (Wilrijk), M.Coeckelberghs (Antwerp), J.-L.Coolens (Hasselt), W. Coucke (Roeselare), E. Couturier (Brussels), R. Craen (Gent), J. C. Daubresse (Charleroi), J. De Cock (Gent), P. De Craene (Bonheiden), F.Defoer (Brussels), C.Delvigne (Antwerp), D. Désir (Brussels), H.Dorchy (Brussels), M. Du Caju (Antwerp), F. Féry (Brussels), C. Gillet (Brussels), G. Krzentowski (Jumet), G. Lamberigts (Brugge), J.-P.Lauvaux (Brussels), P.Lemmens (Ekeren), H.Loeb (Brussels), J. Monballyu (Zoersel), D. Nicolaji (Kortrijk), R.Rottiers (Gent), A.Scheen (Liège), J.-C.Sodoyez (Liège), G. Somers (Brussels), K. Van Acker (Antwerp), P. Van Crombrugge (Aalst), L. Van Gaal (Antwerp), S. Van Imschoot (Brugge), P. Van Rooy (Antwerp), J. Vertommen (Antwerp).

We are endebted to Dr. L.Kaufman (Dept. of Biostatistics, VUB) for expert statistical advice, to A.Demarré, L. De Pree, P. Goubert, A.Ivens, F.Lebleu, E.Quartier and G. Schoonjans for excellent technical assistance, and to N. Ringoot, L. Vermeir and N. Van Slijcke for most reliable secretarial help. JDF standard for ICA determination was kindly donated by Dr. $\AA$. Lernmark (University of Washington, Seattle, USA). Crystalline humulin was a gift of E. Lilly Co, Brussels, Belgium. The present work was supported by the Belgian Fund for Scientific Medical Research (FGWO grant 3-9007-91). The Belgian Diabetes Registry is supported financially by grants from the Belgian National Lottery, the Flemish Ministry of Health, Eastman Kodak and Novo Nordisk. FG is recipient of a fellowship for fundamental clinical research from the Belgian Fund for Scientific Medical Research (FGWO 3-3006-91N).

\section{References}

1. Baekkeskov S, Aanstoot HJ, Christgau Set al. (1990) Identification of the $64 \mathrm{k}$ autoantigen in insulin-dependent diabetes as the GABA-synthesizing enzyme glutamic acid decarboxylase. Nature (Lond) 347: 151-156

2. Christie MR, Tun RYM, Lo SSS et al. (1992) Antibodies to GAD and tryptic fragments of islet $64 \mathrm{~K}$ antigens as distinct markers for development of type 1 diabetes: studies with identical twins. Diabetes 41:782-787
3. Karjalainen J, Martin JM, Knip Met al. (1992) A bovine albumin peptide as a possible trigger of insulin-dependent diabetes mellitus. N Engl J Med 327: 302-307

4. Tarn A, Thomas J, Dean B et al. (1988) Predicting insulin-dependent diabetes. Lancet I: $845-850$

5. Maclaren NK (1988) How, when and why to predict type 1 diabetes. Diabetes 37: 1591-1594

6. Bruining GJ, Molenaar JL, Grobbee DE et al. (1989) Ten-year follow-up study of islet cell antibodies and childhood diabetes mellitus. Lancet I: 1100-1103

7. Ziegler AG, Ziegler R, Vardi P, Jackson RA, Soeldner JS, Eisenbarth GS (1989) Life-table analysis of progression to diabetes of anti-insulin autoantibody-positive relatives of individuals with type 1 diabetes. Diabetes 38:1320-1325

8. Bonifacio E, Bingley PJ, Shattock H et al. (1990) Quantification of islet-cell antibodies and prediction of insulin-dependent diabetes. Lancet 335: 147-149

9. Karjalainen JK (1990) Islet cell antibodies as predictive markers for type 1 diabetes in children with high background incidence of the disease. Diabetes 39:1144-1150

10. Palmer JP, McCulloch DK (1991) Prediction and prevention of type 1 diabetes. Diabetes 40: $943-947$

11. Nepom GT (1990) A unified hypothesis for the complex genetics of HLA associations with type 1 diabetes. Diabetes 39: 11531157

12. Baisch JM, Weeks T, Giles R, Hoover M, Stastry P, Capra JD (1990) Analysis of HLA-DQ genotypes and susceptibility in insulin-dependent diabetes mellitus. N Eng1 J Med 322: 1836-1841

13. Altman DM, Sansom D, Marsh SGE (1991) What is the basis for HLA-DQ association with autoimmune disease? Immunol Today 12: $267-270$

14. Deschamps I, Beressi JP, Khalil I, Robert J (1991) The role of genetic predisposition to type 1 (insulin-dependent) diabetes mellitus. Ann Med 23: 427-435

15. Sheehy MJ (1992) HLA and insulin-dependent diabetes: a protective perspective. Diabetes 41: 123-129

16. Heimberg H, Nagy ZP, Somers G, De Leeuw I, Schuit F (1992) Complementation of HLA DQA and DQB genes confers susceptibility and protection to insulin-dependent diabetes mellitus. Hum Immunol 33: 10-17

17. Ziegler AG, Standl E, Albert E, Mehnert H (1991) HLA-associated insulin autoantibody formation in newly diagnosed type 1 diabetic patients. Diabetes 40: 1146-1149

18. Boehm BO, Manfras B, Seissler S et al. (1991) Epidemiology and immunogenetic background of islet cell antibody-positive nondiabetic schoolchildren. Ulm-Frankfurt population study. Diabetes 40: 1435-1439

19. Deschamps I, Boitard C, Hors J et al. (1992) Life table analysis of the risk of type 1 (insulin-dependent) diabetes mellitus in siblings according to islet cell antibodies and HLA markers. An 8-year prospective study. Diabetologia 35:951-957

20. Gorus FK, Vandewalle CL, Schuit FC, Pipeleers DG and the Belgian Diabetes Registry (1992) Associations between genetic risk markers and autoantibodies in first degree relatives of patients with type 1 diabetes. Diabetologia 35: 208 (Abstract)

21. Eisenbarth GS (1986) Type 1 diabetes mellitus: a chronic autoimmune disease. N Engl J Med 314: 1360-1368

22. Decraene T, Vandewalle CL, Pipeleers DG, Gorus FK and the Belgian Diabetes Registry (1992) Increased concentrations of total IgM at onset of type 1 (insulin-dependent) diabetes: correlation with IgM binding to cells. Clin Chem 38: 1762-1767

23. National Diabetes Data Group (1979) Classification and diagnosis of diabetes mellitus and other categories of glucose intolerance. Diabetes 28: 1039-1057

24. Bodmer JG, Marsh SGE, Parham P et al. (1990) Nomenclature for factors of the HLA system, 1989. Tissue Antigens 35:1-8

25. Gorus FK, Sodoyez J-C, Pipeleers DG et al. (1992) Detection of autoantibodies against islet amyloid polypeptide in human serum. Lack of association with type 1 (insulin-dependent) diabetes mellitus, or conditions favouring amyloid deposition in islets. Diabetologia 35: 1080-1086 
26. Palmer JP, Asplin CM, Clemons P et al. (1983) Insulin antibodies in insulin-dependent diabetics before insulin treatment. Science 222: 1337-1339

27. Srikanta S, Ricker AT, McCulloch DK, Soeldner JS, Eisenbarth GS, Palmer JP (1986) Autoimmunity to insulin, beta cell dysfunction, and development of insulin-dependent diabetes mellitus. Diabetes 35: 139-142

28. Bottazzo GF, Florin-Christensen A, Doniach D (1974) Islet cell antibodies in diabetes mellitus with autoimmune polyendocrine deficiencies. Lancet II: $1279-1283$

29. Baker J, Metcalf P, Scragg R, Johnson R (1991) Fructosamine Test-Plus modified fructosamine assay evaluated. Clin Chem 37: $552-556$

30. De Schepper J, Derde MP, Goubert P, Gorus F (1988) Reference values for serum fructosamine concentrations in children: influence of protein concentration, age and sex. Clin Chem 34 : 2444-2447

31. Reijonen H, Ilonen J, Knip M, Akerblom K (1991) HLA-DQB1 alleles and absence of Asp 57 as susceptibility factors of type 1 diabetes in Finland. Diabetes 40: 1640-1677

32. Karjalainen J, Salmela P, Ilonen J, Surcel HM, Knip M (1989) A comparison of childhood and adult type 1 diabetes mellitus. $\mathrm{N}$ Engl J Med 320: 881-886

33. Landin-Olsson M, Karlsson FA, Lernmark $\AA$, Sundkvist $G$ and the Diabetes Incidence Study in Sweden Group (1992) Islet cell and thyrogastric antibodies in 633 consecutive 15 - to 34 year-old patients in the Diabetes Incidence Study in Sweden. Diabetes 41: 1022-1027

34. Wilkin TJ (1991) Autoantibodies as mechanisms, markers and mediators of B-cell disease. Diab Metab Rev 7: 105-120

35. Palmer JP (1987) Insulin autoantibodies: their role in the pathogenesis of type 1 diabetes. Diab Metab Rev 3: 1005-1015

36. Spinas GA, Matler L, Wilkin T, Staffelbach O, Berger W (1988) Islet-cell and insulin autoantibodies in first degree relatives of type 1 diabetes: a 5-year follow-up study in a Swiss population. Adv Exp Med Biol 246: 209-214

37. Arslanian SA, Becker DJ, Rabin B et al. (1986) Correlates of insulin antibodies in newly diagnosed children with insulin-dependent diabetes before insulin therapy. Diabetes 35: 634-641
38. Wilkin T, Armitage M, Casey C et al. (1985) Value of insulin autoantibodies as serum markers for insulin-dependent diabetes mellitus. Lancet I: 480-482

39. Atkinson MA, Maclaren NK, Riley WJ, Winter WE, Fisk DD, Spillar RP (1986) Are insulin autoantibodies markers for insulindependent diabetes mellitus? Diabetes 35: 894-898

40. Ziegler R, Alper CA, Awdeh ZL et al. (1991) Specific association of HLA-DR4 with increased prevalence and concentrations of insulin autoantibodies in first-degree relatives of patients with type 1 diabetes. Diabetes 40: 709-714

41. Vexiau P, Helmy-Khalil S, Deschamps I et al. (1988) Organ-specific autoantibodies in HLA genotyped insulin-dependent diabetes mellitus families. J Autoimmun 1: 253-261

42. Pagano G, Cavallo-Perin P, Cavalot F et al. (1987) Genetic, immunologic and environmental heterogeneity of type 1 diabetes: incidence and 12-mo follow-up of an Italian population. Diabetes 36: 859-863

43. Dean BM, Becker F, McNally JM et al. (1986) Insulin autoantibodies in the prediabetic period: correlation with islet cell antibodies and development of diabetes. Diabetologia 29:339-342

44. Vardi P, Ziegler AG, Mathews JH et al. (1988) Concentrations of insulin antibodies at onset of type 1 diabetes: inverse log-linear correlation with age. Diabetes Care 11:736-739

45. Caillat-Zucman S, Garchon H-Y, Timsit J et al. (1992) Age-dependent HLA genetic heterogeneity of type 1 (insulin-dependent) diabetes mellitus. J Clin Invest 90: 2241-2250

46. Krolewski AS, Warram JH, Rand LI, Kahn CR (1987) Epidemiologic approach to the etiology of type 1 diabetes mellitus and its complications. N Engl J Med 317: 1390-1398

Received: 29 March 1993

and in revised form: 4 June 1993

Dr. F. K. Gorus

Diabetes Research Centre

Vrije Universiteit BrusseI

Laarbeeklaan 103

B-1090 Brussels

Belgium 